\title{
Dinâmica da inversão do saco vitelino em preás (Galea spixii Wagler, 1831) ${ }^{1}$
}

\author{
André M. Vale ${ }^{2 *}$, Gleidson B. Oliveira ${ }^{2}$, Phelipe 0. Favaron ${ }^{3}$, Maria A. Miglino ${ }^{3}$, \\ Valeria V. Paula' ${ }^{2}$ Alexandre R. Silva² e Moacir F. Oliveira ${ }^{2}$
}

\begin{abstract}
Vale A.M., Oliveira G.B., Favaron P.O., Miglino M.A., Paula V.V., Silva A.R. \& Oliveira M.F. 2013. [Dynamics of yolk sac inversion in galea (Galea spixii Wagler, 1831).] Dinâmica da inversão do saco vitelino em preás (Galea spixii Wagler, 1831). Pesquisa Veterinária Brasileira 33(8):1033-1040. Programa de Pós-Graduação em Ciência Animal, Universidade Federal Rural do Semi-Árido, BR 110 Km 47, Rodovia Presidente Costa e Silva s/n, Mossoró, RN 59625-900, Brazil. E-mail: andre_bioquimico@hotmail.com

The aim of this study was to study the time of yolk sac inversion as well as the dynamics resulting from this process in galea throughout pregnancy. For this, conventional histological techniques, scanning electron microscopy and transmission electron microscopy were used. Parietal and visceral endoderm delimiting the yolk sac cavity was observed at 12 days of pregnancy. The parietal endoderm was coating the fetal surface of the chorioallantoic placenta as well as delimiting the decidua capsularis area. This endoderm had prismatic format and were apart from the trophoblast by an enlarged Reichert's membrane. The visceral endoderm had vitelline vessels and there were villi only in certain areas. At 14 days of pregnancy the yolk sac inversion was characterized by the degeneration of parietal endoderm and mural trophoblast, and also the gradual disappearance of the Reichert's membrane. So it made the visceral endoderm establish an interface with the uterine epithelium. After the inversion, the parietal endoderm which remained intact was the one that rested on the chorioallantoic placenta surface. It presented cells with high columnar format and pseudostratified epithelium featured. The visceral endoderm presented many apical villi, especially in areas close to the chorioallantoic placenta. The continued development of the embryo and chorioallantoic placenta evidenced the emergence of an important apposition area between visceral and parietal endoderm. The yolk sac inversion represented an anatomical arrangement in favor of the embryo development as well as an evolutionary trait in this rodent species.
\end{abstract}

INDEX TERMS: Galea, Galea spixii, yolk sac, visceral endoderm, parietal endoderm, inversion.

RESUMO.- 0 objetivo deste trabalho foi estudar o período de inversão do saco vitelino bem como a dinâmica resultante deste processo na gestação inicial em preás, utilizando-se microscopia de luz, microscopia eletrônica de varredura e de transmissão. No décimo segundo dia de gestação observou-se o desenvolvimento dos endodermas parietal

\footnotetext{
${ }^{1}$ Recebido em 12 de setembro de 2012.

Aceito para publicação em 2 de maio de 2013.

${ }^{2}$ Programa de Pós-Graduação em Ciência Animal, Universidade Federal Rural do Semi-Árido (UFERSA), Mossoró, RN 59625-900, Brasil. *Autor para correspondência: andre_bioquimico@hotmail.com

${ }^{3}$ Programa de Pós-Graduação em Anatomia dos Animais Domésticos e Silvestres, Faculdade de Medicina Veterinária e Zootecnia, Universidade de São Paulo, Av. Prof. Dr. Orlando Marques de Paiva 87, Cidade Universitária, São Paulo, SP 05508-270, Brasil.
}

e visceral delimitando a cavidade do saco vitelino. 0 endoderma parietal foi evidenciado revestindo a superfície fetal da placenta corioalantoidea bem como contornando o espaço delimitado pela decídua capsular. Estes endodermas apresentaram formato prismático e encontraram-se separados do trofoblasto por uma desenvolvida membrana de Reichert. Já o endoderma visceral continha vasos vitelínicos e possuía vilosidades apenas em determinadas áreas. No décimo quarto dia de gestação verificou-se a inversão do saco vitelino, caracterizada pela degeneração do endoderma parietal e trofoblasto mural, associado ao desaparecimento gradual da membrana de Reichert. Como consequência deste fenômeno, o endoderma visceral passou a constituir uma interface com o epitélio uterino. Após a inversão, o endoderma parietal que permaneceu íntegro foi 
aquele que se apoiava na superfície da placenta corioalantóidea, apresentando células em formato colunar alto e característica de epitélio pseudoestratificado. 0 endoderma visceral apresentou numerosas vilosidades apicais principalmente em regiões próximas a placenta corioalantóidea. Com o contínuo desenvolvimento do embrião e placenta corioalantóidea, observou-se o surgimento de importante área de aposição entre os endodermas visceral e parietal. A inversão do saco vitelino representou uma disposição anatômica favorável ao desenvolvimento embrionário, além de ser uma característica evolutiva nesta espécie de roedor.

TERMOS DE INDEXAÇÃO: Préa, Galea spixii, saco vitelino, endoderma visceral, endoderma parietal, inversão.

\section{INTRODUÇÃO}

A utilização de roedores em pesquisas envolvendo aspectos funcionais da placenta, seja ela corioalantóidea ou vitelina, vem sendo cada vez mais requisitado, mediante as vantagens apresentadas por esses animais. Essas vantagens vão desde características da biologia, principalmente àquelas relacionadas ao pequeno porte, baixo custo de manutenção e curto período de gestação, até a semelhança com a placenta e o processo de placentação em humanos, uma vez que ambos possuem uma placenta discoidal, corioalantóidea e hemocorial, o que torna os roedores um interessante modelo experimental para o entendimento da placentação e mecanismos fisiológicos e moleculares de trocas materno-fetais (Carter 2007). Embora a grande maioria dessas características tenha permanecido estáveis ao longo da evolução dos roedores, trabalhos tem mostrado que pode haver variações relacionadas à presença de estruturas acessórias à placenta corioalantóidea, como é o caso da subplacenta nos roedores da Subordem Histricomorfa (Miglino et al., 2004, Bonatelli et al. 2005, Oliveira et al. 2006, 2008 e 2012a) e das características do saco vitelino, que nas diferentes espécies de roedores de um modo geral, forma uma placenta vitelina invertida ativa para trocas materno-fetais, presente até o final da gestação (Mossman 1987, Miglino et al. 2008, Favaron et al. 2011, 2012, Oliveira et al. 2012a, 2012b).

0 saco vitelino é a primeira membrana que se forma com a função de estabelecer trocas entre a mãe e o embrião (Mossman 1987). Embora seja sabido que o mesmo desempenha muitas e importantes funções ao longo de toda a gestação, as características relacionadas ao seu desenvolvimento, especialmente com relação à formação da placenta vitelina invertida nos roedores, ainda são bastante escassos (Conceição et al. 2008, Miglino et al. 2008, Oliveira et al. 2012b).

Na gestação inicial desenvolve-se o saco vitelino cuja conformação espacial dos seus endodermas origina a placenta vitelina. A membrana fetal mais externa refere-se ao endoderma parietal que reveste tanto a superfície da placenta corioalantóidea -ou principal- quanto o trofoblasto mural, delimitando todo o saco gestacional. 0 endoderma visceral possui localização mais interna apresentando uma região de inserção na placenta principal e ainda acompanha todo o contorno promovido pelo endoderma parietal (Anderson 1959, Jollie 1990).
A inversão do saco vitelino constitui a característica mais marcante que ocorre nas membranas fetais dos roedores, sendo um fenômeno resultante da degeneração do endoderma parietal, membrana de Reichert subjacente e trofoblasto mural. Como consequência, o endoderma visceral passa a formar uma interface com o tecido materno, tornando-se exposto as secreções produzidas pelas glândulas uterinas (King 1982, Mossman 1987, Jollie 1990).

0 saco vitelino invertido de roedores desempenha várias funções podendo-se destacar aquelas relacionadas ao armazenamento, absorção e transferência de nutrientes (Laliberté et al. 1984, Carter 2001, Holson et al. 2005, Favaron et al. 2012). De fato, distúrbios nestas funções produzidas por agentes teratogênicos, por exemplo, podem explicar possíveis doenças no recém-nascido (Jollie 1990). Esses mecanismos podem ser melhor compreendidos pelo conhecimento da morfofisiologia do saco vitelino e o consequente processo de inversão dessa membrana fetal.

Neste estudo buscou-se descrever o processo de inversão do saco vitelino no preá, um pequeno roedor pertencente à subordem Hystricomorpha e família Caviidae, bem como a morfofisiologia dessa membrana na fase inicial da gestação, utilizando-se de técnicas de microscopia de luz, eletrônica de varredura e de transmissão.

\section{MATERIAL E MÉTODOS}

Foram utilizadas 30 fêmeas não gestantes de preás para formação de cinco grupos experimentais contendo seis fêmeas cada. Os animais foram obtidos no Centro de Multiplicação de Animais Silvestres da Universidade Federal Rural do Semi-Árido, registrado junto ao IBAMA como criadouro científico sob o número 1478912. As respectivas fêmeas foram alocadas em boxes de $5 \mathrm{~m}^{2}$ nos quais foi fornecida alimentação apropriada e água ad libitum. Para diferenciação destas, foram realizadas marcações com tintura capilar negra, em diferentes regiões anatômicas seguidas da adição de um macho em cada box. A cópula e o consequente início de gestação foram detectados mediante exames de citologia vaginal, onde a presença dos espermatozoides culminaram com a separação do box no qual a fêmea se encontrava para a realização da coleta dos sacos gestacionais. Para tanto, os animais foram pesados e pré-medicados com a associação de cloridrato de xilazina (1 mg. $\mathrm{kg}^{-1}$ ) e cetamina (15mg.kg-1) seguida da overdose anestésica de tiopental sódico (50mg.kg-1) e administração de cloreto de potássio 2,56mEq. $\mathrm{kg}^{-1}$ ambos por via intravenosa. Constatada a morte do animal, realizou-se uma incisão longitudinal mediana, de forma a expor o útero gravídico para retirada dos sacos gestacionais.

A detecção da inversão do saco vitelino e ainda a definição do período da sua ocorrência foram realizados mediante análises de sacos gestacionais com 11,12, 14, 15, 25 e 30 dias de gestação, até que se fosse evidenciada uma disposição das membranas fetais em situação anterior a inversão. Uma vez que a inversão do saco vitelino foi evidenciada no $14^{\circ}$ dia de gestação, atenção especial foi dada a esse período. Para tanto, foram processados e analisados três sacos gestacionais com 14 dias de gestação, oriundos de diferentes fêmeas de modo a ratificar o processo de inversão. Desta forma, todas as amostras foram fixadas em solução de paraformaldeído $4 \%$ tamponado e transferidos para uma série de concentrações crescentes de álcoois (70-100\%). Posteriormente, os sacos gestacionais foram diafanizados em xilol e embebidos em parafina histológica $\left(\right.$ Synt $^{\circledR}$, granulada com ponto de fusão $58^{\circ} \mathrm{C}$ a $62^{\circ} \mathrm{C}$, lote: 138199 ) para obtenção dos blocos. Estes últimos 
foram cortados a $5 \mu \mathrm{m}$ de espessura em micrótomo (LEICA RM $2125 \mathrm{RT}^{\circledR}$ ), sendo os cortes aderidos em lâminas histológicas e corados segundo a técnica de hematoxilina e eosina (HE), azul de toluidina (AT) e ácido periódico de Schiff (PAS). As imagens mais representativas foram fotomicrografadas em microscópio óptico (Olympus CX 31 RBSFA $^{\circledR}$ ).

A microscopia eletrônica de varredura foi realizada mediante o processamento de um saco gestacional de 30 dias, o qual foi fixado em glutaraldeído 2,5\% tamponado e pós-fixado em tetróxido de ósmio 1\%. Em seguida, foram realizadas três lavagens em tampão fosfato $0,1 \mathrm{M}$ e pH 7,4 e duas, com água destilada para tratamento posterior com ácido tânico 1\% e desidratação em diferentes concentrações de álcoois (50\%, 70\%, 90\% e 100\%). Finalizada a desidratação foi feita a secagem em aparelho de ponto crítico utilizando gás carbônico. As seguintes etapas consistiram na montagem do material em suporte de amostra (Stub) e recobrimento metálico com ouro por "sputtring", para observação em microscópio eletrônico de varredura (LEO VP ${ }^{\circledR}$ 435- Carls-Zeis, Oberkochen, Germany).

Para análise ultraestrutural, utilizaram-se fragmentos com $0,5 \mathrm{~cm}^{2}$ da placenta vitelina visceral obtida no décimo quarto dia de gestação. Estes foram fixados em glutaraldeído a 2,5\% tamponado e pós-fixados em tetróxido de ósmio. Após este procedimento, os fragmentos foram lavados em solução tampão de fosfato de sódio e desidratados em concentrações crescentes de álcool etílico: $50 \%, 70 \%, 80 \%, 90 \%$ e $100 \%$. Os fragmentos foram submetidos a lavagens em óxido de propileno sob rotação e depois, imersos em óxido de propileno e resina Spurr. Finalmente, foram colocados em contado com resina Spurr pura, em moldes específicos, para polimerização. Obtidos os blocos, foram realizados cortes semifinos com $0,4 \mathrm{~mm}$ de espessura em ultramicrótomo au- tomático (Ultracut R, Leica Microsystens - Germany), corados com azul de Toluidina a $1 \%$ para identificação de regiões específicas de interesse para o trabalho de forma a possibilitarem a realização dos cortes ultrafinos. Posteriormente, cortes de $0,07 \mathrm{~mm}$ de espessura foram coletados em telas de cobre e contrastados com acetato de uranila saturado a $2 \%$ e citrato de chumbo a $0,5 \%$. 0 material foi analisado em microscópio eletrônico de transmissão (Morgagni 268D, FEI Company, The Netherlands; Mega View III câmera, Soft Imaging, Germany).

\section{RESULTADOS}

No décimo segundo dia de gestação, verificou-se o desenvolvimento de uma placenta corioalantóidea acompanhado da formação dos endodermas visceral e parietal delimitando a cavidade do saco vitelino e constituindo a placenta vitelínica. 0 endoderma parietal revestiu a superfície da placenta corioalantóidea, bem como a região da decídua capsular (Fig.1A). Este endoderma apresentou-se separado do trofoblasto e útero por uma desenvolvida membrana basal de Reichert a qual se apresentou positiva para a reação do ácido periódico de Schiff (PAS) como observado na (Fig.1B). Nestes locais, as células endodérmicas apresentaram formato colunar e numerosas vilosidades ao longo do disco placentário. Já a porção de endoderma parietal que se encontrava associado ao trofoblasto mural e desta forma, circunscrevia toda a área da decídua capsular, apresentou grânulos glicoproteicos fortemente positivos para a reação PAS nas superfícies apicais das células endodérmicas. Estas células possuíram morfologia prismática e apoiavam-se

Fig.1. Disposição do endoderma parietal antes da inversão em preás aos 12 dias de gestação. (A) Corte transversal do saco gestacional demonstrando o revestimento das células endodérmicas parietais (seta preta) na superfície da placenta corioalantóide (PL) e no útero (U) (seta vermelha). Hematoxilina e eosina (HE). (B) Corte transversal do saco gestacional evidenciando o revestimento endodérmico parietal do saco vitelino (EP) no útero (U) e placenta principal $\left({ }^{*}\right)$; observar a proeminente membrana de Reichert (setas) positiva para a reação do ácido periódico de Schiff. Ácido Periódico de Schiff. (C) Observar a membrana de Reichert $\left({ }^{*}\right)$ separando o endoderma parietal (EP) do sincício marginal da placenta corioalantóidea (PL). Microscopia eletrônica de varredura. (D) Região distante da placenta corioalantóidea; observar o útero (U), o trofoblasto mural (TM) e os endodermas parietal (EP) e visceral (EV) delimitando a cavidade do saco vitelino (*). A seta preta refere-se à membrana basal de Reichert. Ácido Periódico de Schiff.
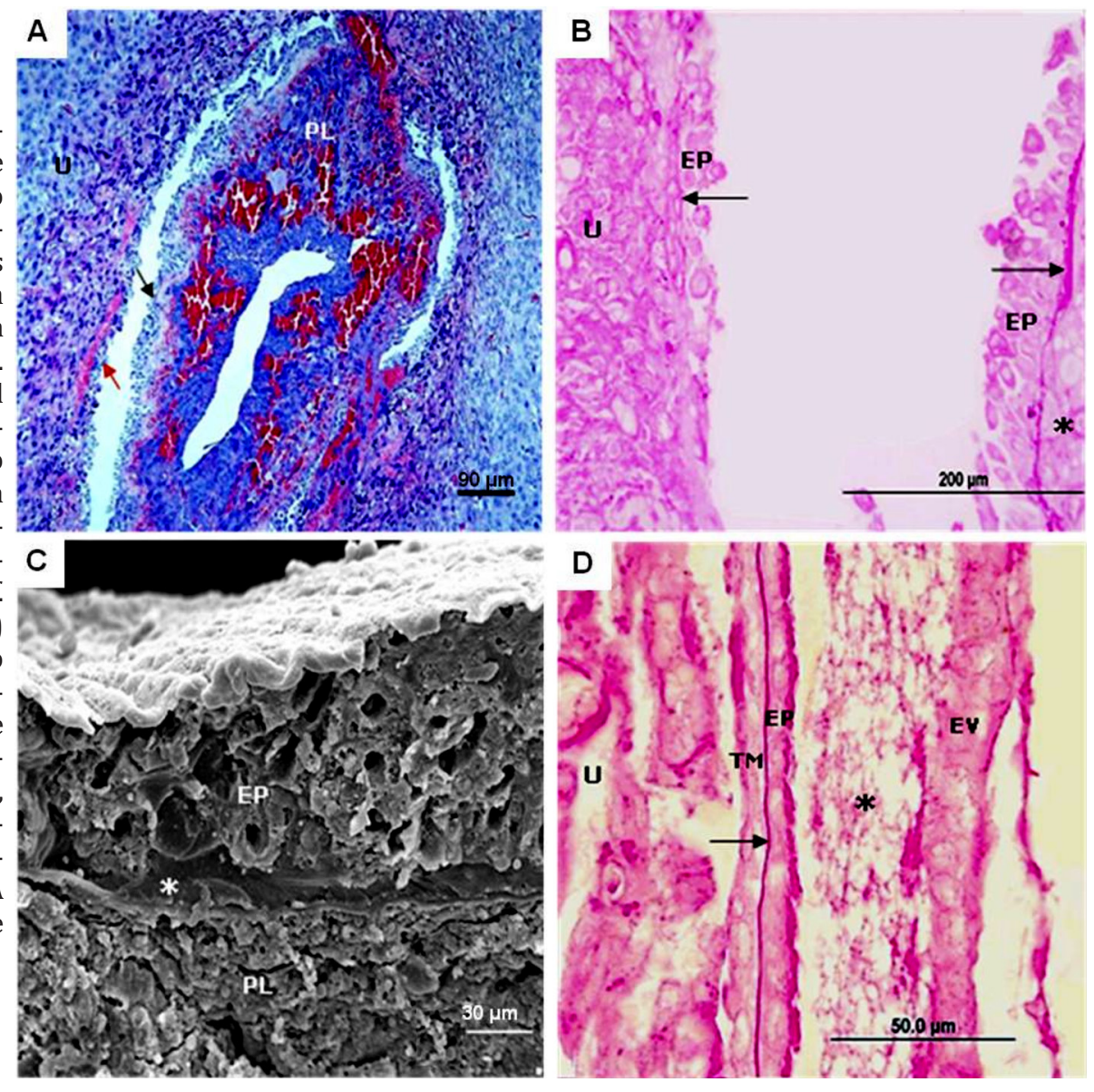

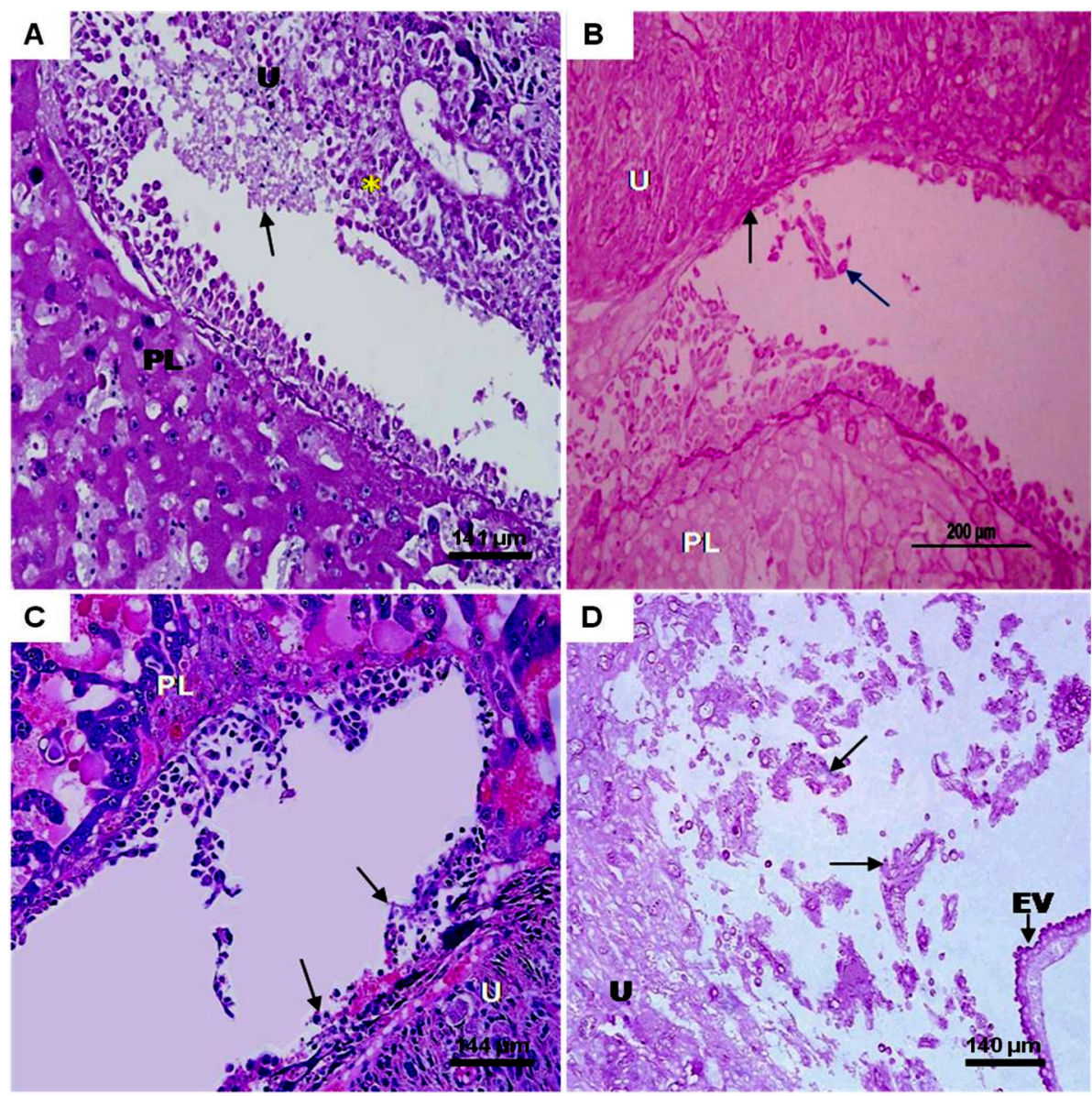

Fig.2. Inversão do saco vitelino no décimo quarto dia de gestação em três sacos gestacionais de preás. (A) Saco gestacional um (SG1); notar o início da degeneração da onfalopleura bilaminar $\left({ }^{*}\right)$ e extravasamento de sangue materno (seta) no interstício entre a placenta corioalantóidea (PL) e o útero (U). HE. (B) Saco gestacional dois (SG2); observar a degeneração de células endodérmicas parietais (seta azul) opostas à placenta corioalantóidea (PL) e escassez da membrana de Reichert (seta preta) distribuída apenas em alguns locais próximo à parede do útero (U). Ácido periódico de Schiff. (C,D) As figuras fazem referência ao saco gestacional três (SG3). (C) Desorganização epitelial do endoderma parietal (setas) revestindo a superfície do útero (U) em região próxima à placenta corioalantóidea (PL). HE. (D) Extrema degeneração de células parietais (setas) próximo à parede uterina (U) e a presença do endoderma visceral (EV). Ácido periódico de Schiff. na membrana basal de Reichert cujo aspecto contínuo foi bem evidenciado pela microscopia eletrônica de varredura (Fig.1C). Em disposição mais interna, acompanhando o endoderma parietal e envolvendo o embrião, evidenciou-se o endoderma visceral que por sua vez era vascularizado pelo mesoderma subjacente que continha vasos sanguíneos vitelínicos (Fig.1D).
O décimo quarto dia da gestação foi caracterizado pela inversão do saco vitelino. Nos três botões embrionários analisados, observou-se elevada desorganização estrutural das células endodérmicas parietais que revestiam a decídua capsular. Devido ao fato da presença de pequenas diferenças individuais terem sido observadas em cada saco gestacional analisado, procurou-se descrever as respecti-
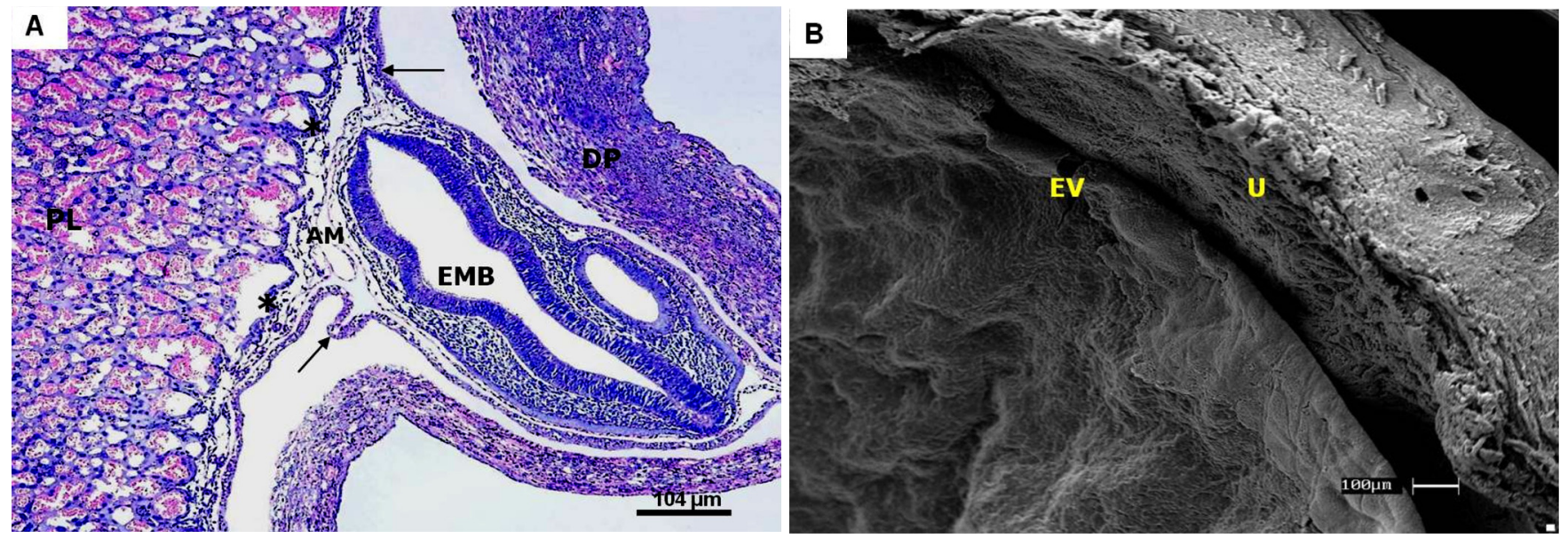

Fig.3. Componentes do saco gestacional de preás aos 15 dias de gestação. (A) Observar o desenvolvimento da placenta corioalantóidea $(\mathrm{PL})$, embrião (EMB) e âmnio (AM) resultando em aproximações dos endodermas visceral (setas) e parietal ( ${ }^{*}$ ) na região da placenta principal. Notar ainda a decídua parietal (DP) estabelecida após a inversão do saco vitelino. HE. (B) Confluência entre o endoderma visceral (EV) e o útero (U). Microscopia eletrônica de varredura. 
vas modificações observadas denominando cada amostra como saco gestacional um (SG1), dois (SG2) e três (SG3). No SG1 verificaram-se degeneração inicial da onfalopleura bilaminar, localizada próxima à placenta principal e áreas de sangue materno extravasado (Fig.2A). Já no SG2 evidenciaram-se degenerações do endoderma parietal e a presença de resquícios da membrana de Reichert em aposição ao tecido uterino (Fig.2B). No SG3 o revestimento epitelial de endoderma parietal apresentou-se descontínuo próximo à placenta principal e completamente desestruturado em locais distantes da mesma (Fig.2C,D).

No décimo quinto dia de gestação destacaram-se as expansões do embrião e placenta corioalantóidea, além do endoderma visceral que circunscrevia todo o contor-
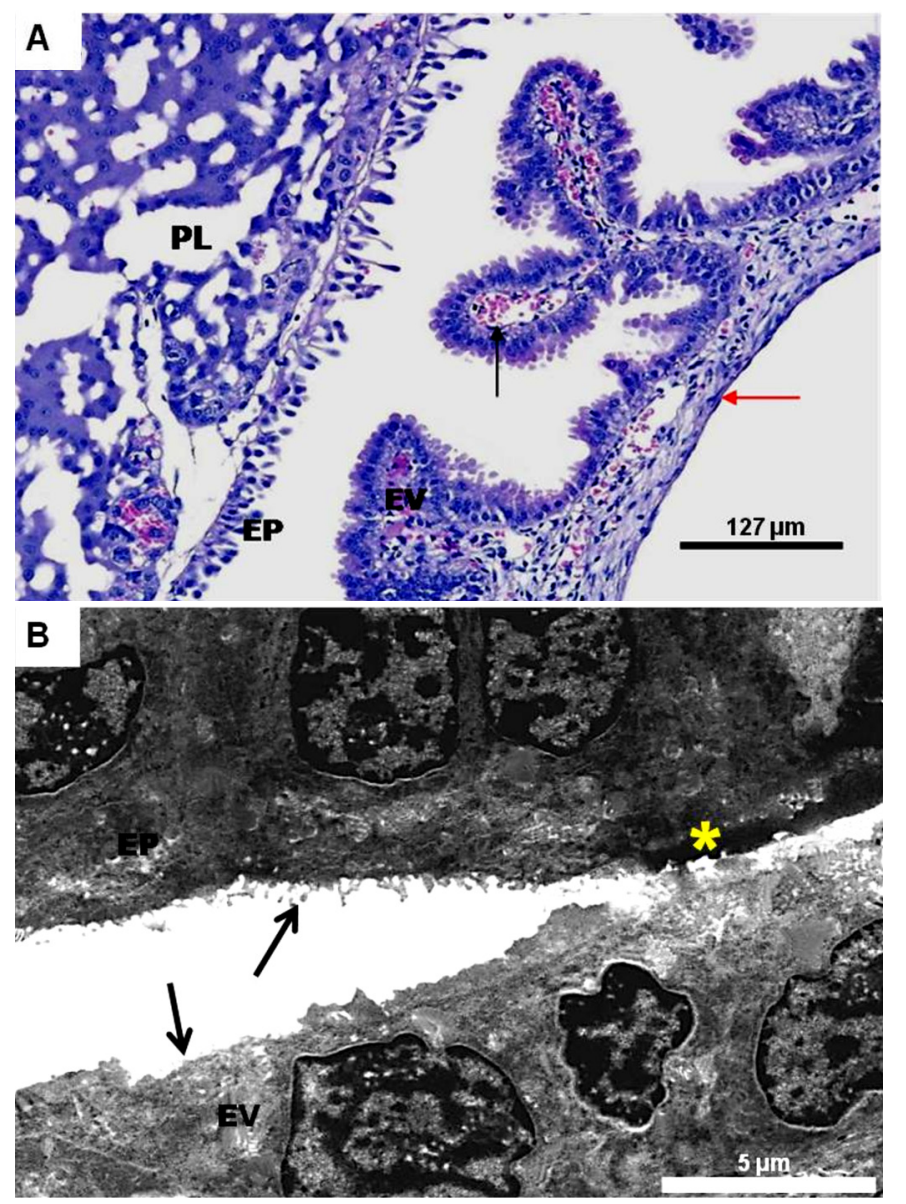

Fig.4. Relações de aposição entre os endodermas visceral (EV) e parietal (EP) as margens da placenta corioalantóidea (PL) em preás aos 25 dias (Fig.A) e no décimo quarto dia de gestação (Fig.B). (A) Formação de tufos ou vilos do endoderma visceral com respectivos núcleos na posição basal da célula; notar a membrana basal visceral (seta preta) e membrana basal serosa (seta vermelha) formando o alicerce do epitélio visceral. Azul de toluidina. (B) Eletromicrografia dos endodermas visceral (EV) e parietal (EP) as margens da placenta corioalantóidea em preás aos 14 dias de gestação. Observar as relações de aposição entre as células e as numerosas microvilosidades apicais (setas) proporcionando possíveis áreas de trocas entre os endodermas. Notar as áreas em que os dois epitélios mantém íntimo contato $(*)$. Microscopia eletrônica de transmissão. no da decídua parietal. Com o rompimento da onfalopleura bilaminar criou-se um mecanismo de aposição entre o endoderma visceral e útero de modo a garantir efetivas trocas de substâncias entre os tecidos maternos e fetais. Desta forma, as células endodérmicas viscerais tornavam-se completamente expostas ao conteúdo secretado pelas glândulas uterinas (Fig.3A,B).

As relações de aposição verificadas entre os endodermas localizados próximos à placenta corioalantóidea favoreceram a interpretação de importantes locais para o intercâmbio de substâncias, constituindo vias bidirecionais entre placenta e embrião. Nestes locais, as células viscerais possuíram formato colunar, numerosas vilosidades e núcleos localizados na posição basal da célula. Além disso, tornou-se evidente aos 25 dias de gestação, a caracterização da esplancnopleura como sendo constituída por células endodérmicas viscerais que repousavam sobre uma lâmina basal visceral. Já na superfície externa do epitélio visceral, evidenciou-se uma segunda membrana basal revestindo as células mesoteliais que margeavam o celoma extraembrionário, sendo denominada membrana basal serosa (Fig.4A).

Nas margens da placenta corioalantóidea, verificaram-se processos de aposição entre os endodermas visceral e parietal, sendo suas vilosidades confluentes. De fato, esta relação estrutural pode vir a conferir possíveis rotas de transferências de substâncias ao embrião constituindo uma importante placenta vitelina (Fig.4B).

Conforme descrito, as modificações verificadas no tocante à disposição espacial das membranas fetais do saco gestacional conferem certo dinamismo ao processo de inversão, fato este demonstrado também de forma esquemática (Fig.5A-C) para facilitar o entendimento relativo a este processo.

\section{DISCUSSÃO}

A compreensão da organização estrutural da placenta vitelina ao longo do período gestacional favorece o estabelecimento de correlações com os aspectos funcionais do saco vitelino. Muitas pesquisas avaliam a estrutura fina das células endodérmicas viscerais e parietais no que diz respeito ao aparato absortivo bem como das organelas citoplasmáticas presentes neste epitélio. Este fato permite ressaltar a importância de uma placenta vitelina invertida seja para aumentar a contínua demanda anabólica do embrião ou até mesmo como uma característica evolutiva das muitas espécies de roedores.

King \& Enders (1970) admitiram a importância de um órgão placentário, na cobaia (Cavia porcellus) e em muitas outras espécies de roedores, para transferência de nutrientes ao feto, sendo os mecanismos de transporte de substâncias desencadeados por dois tipos de placentas, uma corioalantóidea e outra denominada placenta vitelina invertida.

Para Calarco \& Moyer (1966) a placenta vitelina possui geralmente importância secundária, persistindo como estrutura acessória. No entanto, em muitas espécies de roedores, o saco vitelino apresenta contínuo desenvolvimento durante todo o período gestacional, envolve e protege o embrião além de funções nutritivas e hematopoiéticas. Como brevemente reportado no preá por Oliveira et al. (2012b), 


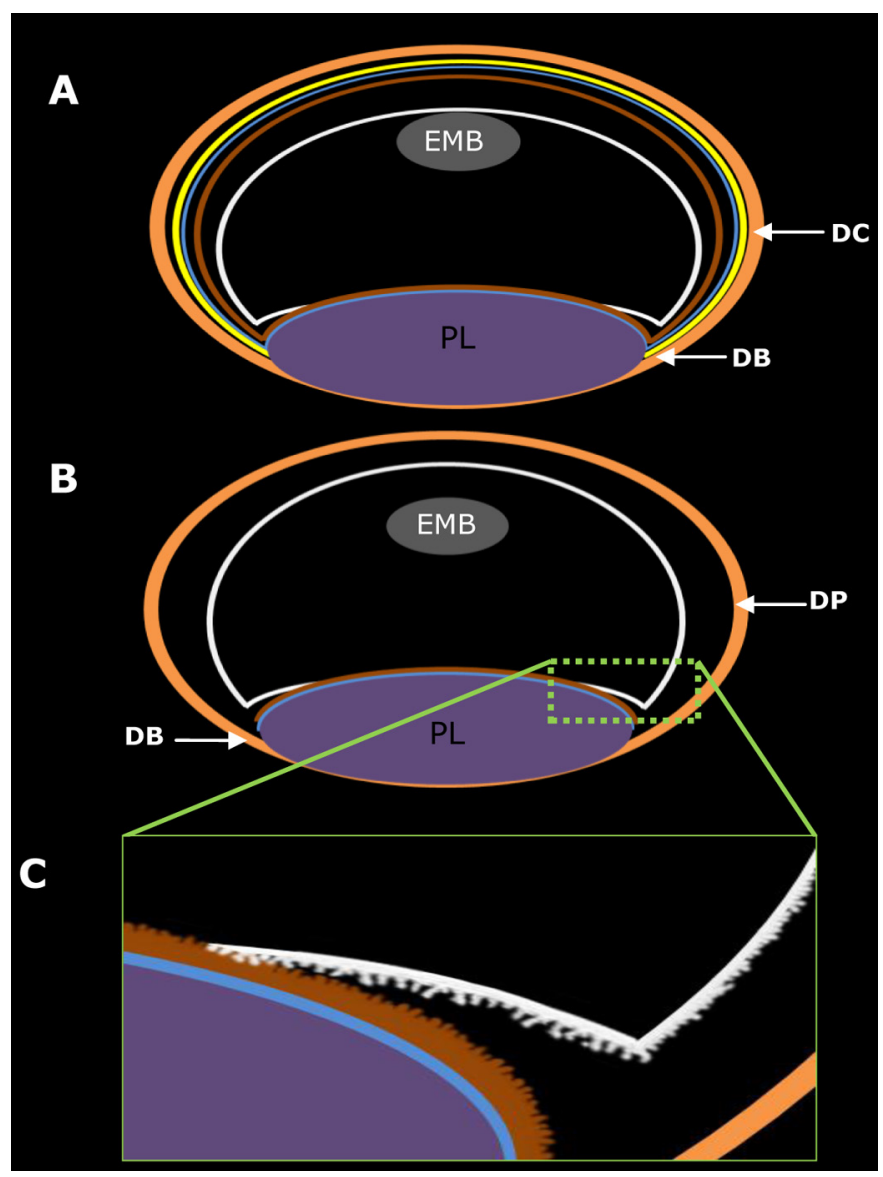

Fig.5. Representação esquemática dos elementos que compõe o saco gestacional em situação anterior e após a inversão do saco vitelino. (A) Disposição das membranas antes da inversão. Observar o útero, constituído pelas decíduas capsular (DC) e basal (DB). Evidenciar o trofoblasto mural (em amarelo), a membrana de Reichert (em azul) acompanhando todo o contorno do trofoblasto mural e ainda, localizando-se na superfície fetal da placenta corioalantóidea (PL). Em marrom, evidencia-se o endoderma parietal, contornando a membrana de Reichert e revestindo a superfície fetal da placenta corioalantóidea. Em conjunto, trofoblasto mural, membrana de Reichert e endoderma parietal são denominados onfalopleura bilaminar. Observar o endoderma visceral (em branco) e as localizações da placenta corioalantóidea e do embrião (EMB). (B) Evidencia-se uma situação posterior à inversão, ocasionada pela degeneração da onfalopleura bilaminar, resultando em íntima relação entre o endoderma visceral e útero. Este último passa a ser constituído pelas decíduas parietal (DP) e basal (DB). Notar ainda a sintopia com a placenta corioalantóidea (PL) e embrião (EMB). (C) Detalhe das vilosidades dos endodermas parietal (membrana marrom) e visceral (membrana em branco) em região proximal a placenta corioalantóidea, representando importantes locais para o intercâmbio de substâncias.

os autores evidenciaram a presença de células proliferativas nas vilosidades do saco vitelino visceral até o dia 30 de gestação, além de uma intensa vascularização e intima relação com a parede uterina. Assim como mencionado por Beckman et al. (1990), onde o autor afirma que o saco vitelino visceral constitui um importante órgão placentário em roedores, pois estabelece os primeiros mecanismos de in- tercâmbio nutricional antes da placenta corioalantóidea se tornar desenvolvida. Mesmo após o estabelecimento desta última, as células do endoderma visceral permanecem funcionais durante toda a gestação, desencadeando diversas funções metabólicas, secretoras e imunológicas.

A atividade das células vitelinas, principalmente do endoderma do saco vitelino em fases mais tardias de gestação (meio e final de gestação) também foi descrita para outras espécies de roedores histricomorfos como a paca (Cuniculus paca), cutia (Dasyprocta leporina), mocó (Kerodon rupestris) e porquinho da Índia (Guinea pig), mediante utilização de técnicas de imunohistoquímica e microscopia eletrônica de transmissão (Bonatelli et al. 2005, Oliveira et al. 2006, 2008, 2012a, 2012b, Conceição et al. 2008, Miglino et al. 2008).

Anderson (1959) ao analisar a placenta vitelina de ratos com o auxilio da microscopia de luz, constatou que a partir do décimo primeiro dia de gestação o saco vitelino era bem desenvolvido, contrastando com a presença de uma imatura placenta corioalantóidea. 0 autor destacou que a placenta vitelina era constituída inicialmente por duas membranas endodérmicas: uma visceral e outra parietal, delimitando a cavidade do saco vitelino. A camada parietal que revestia a decídua capsular apoiava-se numa membrana hialina de Reichert e suas células endodérmicas demonstravam formato colunar baixo, além de curtas microvilosidades apicais. Na superfície do epitélio visceral e abaixo da membrana basal que sustentava este epitélio, verificaram-se curtas vilosidades e poucos vasos vitelínicos respectivamente. Os resultados obtidos em preás demonstraram comportamento similar aos descritos por Anderson (1959) nos períodos estudados antes da inversão do saco vitelino. É importante destacar que a disposição do epitélio visceral apresentou comportamento relativamente constante a partir do décimo quarto dia de gestação, sendo evidenciadas áreas de intensa formação vilosa cujo aspecto convoluto direcionava-se para o endoderma parietal da superfície da placenta principal. Já nos locais distais desta placenta, verificavam-se células prismáticas dotadas de poucas vilosidades, podendo ser caracterizadas como região lisa do endoderma visceral. Tais características estão de acordo com as observações produzidas por Sansom (1922), Wislocki et al. (1946), Anderson (1959), Jollie (1990), Oliveira et al. (2008) e Freyer \& Renfree (2009) para outras espécies de roedores.

A presença de moléculas de glicogênio e/ou substâncias glicoproteicas foram reveladas pela reação de PAS, principalmente nos endodermas parietal e visceral, membrana de Reichert e alguns locais na decídua parietal. Não foram observadas reações positivas para o PAS no sincício marginal da placenta corioalantóidea. Este padrão de positividade de PAS retratado anteriormente mostra-se compatível com aqueles descritos por Haar \& Ackerman (1971) para o saco vitelino de camundongo e por Favaron et al. (2011, 2012) para espécies de roedores cricetídeos.

A partir do décimo segundo dia de gestação em preás, verificou-se a presença da membrana de Reichert que se encontrou interposta entre o endoderma parietal e o trofoblasto da placenta corioalantóidea bem como entre o epi- 
télio parietal e trofoblasto mural da decídua capsular. Essa membrana também foi descrita na placenta de roedores cricetídeos por Favaron et al. (2011) em estágios de meio e final de gestação. Como relatado pelos autores, a mesma possuía uma natureza acelular formada por fibras de natureza colágena.

No décimo quarto dia de gestação em preás, verificou-se o crescimento embrionário e da placenta principal, resultando em aproximações entre o endoderma visceral e parietal as margens da placenta corioalantóidea. Para Cross (1998) esta interface entre os endodermas resulta das transformações e crescimento assimétrico do embrião, acarretando em mudanças espaciais do endoderma visceral e âmnio. Nesta área de interface, as células endodérmicas apresentaram formato poliédrico, núcleos na posição basal e numerosas vilosidades na posição apical, demonstrando o aparato absortivo nesta região da placenta vitelina.

Em preás as projeções vilosas do endoderma visceral, na região do disco placentário, tornaram-se mais ramificadas a partir do vigésimo quinto dia de gestação, conforme evidenciado pela microscopia de luz, sendo o alicerce das formações vilosas constituídos pela membrana basal visceral e serosa. Segundo Mossman (1987) estas ampliações dos processos digitiformes são decorrentes da inversão do saco vitelino, tornando as bordas apicais do epitélio visceral mais suscetível à captação de substâncias. Consequentemente, as vilosidades aumentam em número e tamanho, acompanhando o desenvolvimento das células viscerais as quais se tornam colunares altas (Dempsey 1953, Anderson 1959, King \& Enders 1970).

0 endoderma parietal em preás apresentou mudanças importantes durante o período em que foi analisado. Inicialmente aos 12 dias de gestação, foi constituído por células prismáticas ou cuboidais, contendo numerosos grânulos apicais positivos para a reação PAS e elevada relação núcleo/citoplasma. Posteriormente, evidenciou-se aos 25 dias de gestação, aspecto pseudoestratificado do epitélio parietal com células de formato predominantemente colunar. Padrões semelhantes de desenvolvimento foram evidenciados por King (1971) ao analisar a diferenciação do endoderma parietal no porquinho da Índia (Cavia porcellus), porém foi diferente da caracterização realizada por Jollie (1968). Segundo este autor, o endoderma parietal do rato ou camundongo mantém forma achatada ou esférica ao longo do período gestacional.

Os resultados por microscopia de luz obtidos em preás demonstraram, durante a inversão, desorganização estrutural do endoderma parietal e desaparecimento gradual da membrana de Reichert. É importante ressaltar que existe a possibilidade de variações no período da inversão, pois muitos fatores individuais podem contribuir para a cinética do desenvolvimento embrionário, acarretando, por sua vez, em alterações capazes de influenciar os mecanismos da inversão. No presente estudo, no entanto, verificou-se homogeneidade no tocante ao período de inversão conforme foi evidenciado nos três sacos gestacionais estudados no décimo quarto de dia de gestação.

A grande maioria dos trabalhos disponíveis hoje na literatura sobre a morfologia do saco vitelino trata, princi- palmente, de amostras oriundas de estágios tardios de gestação, principalmente devido às dificuldades para se obter amostras de placenta e das membranas extra-embrionárias em fases inicias. Especificamente no caso do saco vitelino, isso leva a uma lacuna no conhecimento, principalmente relacionado à formação da placenta vitelina, tão importante no início da gestação, inclusive na gestação humana, e cujo correto desenvolvimento leva ao progresso da gestação e consequente sucesso do desenvolvimento embrionário e fetal. Os resultados obtidos no presente estudo permitiram afirmar que em preás ocorre um modelo de placentação vitelínica invertida, cuja inversão propriamente dita ocorre a partir do décimo quarto dia da gestação. Para trabalhos futuros, uma analise quantitativa através de técnicas inovadoras, como a estereologia, associada a analises estatísticas, como no trabalho realizado por Favaron et al. (2013) em diferentes regiões da placenta de Necromys lasiurus (Cricetidae), poderá trazer dados numéricos sobre a dinâmica do desenvolvimento do saco vitelino, bem como do volume ocupado por essa membrana e suas diferentes porções (parietal e visceral) e dos diferentes tipos celulares constituintes ao longo da gestação, resultando em dados funcionais sobre a participação da placenta vitelina nos diferentes estágios gestacionais do preá.

\section{REFERÊNCIAS}

Anderson J.W. 1959. The placental barrier to gamma-globulins in the rat. Am. J. Anat. 104:403-429.

Beckman D.A., Koszalka T.R., Jensen M. \& Brent R.L. 1990. Experimental manipulation of the Rodent visceral yolk sac. Teratology 41:395-404.

Bonatelli M., Carter A.C., Machado M.R.F., Oliveira M.F., Lima M.C. \& Miglino M.A. 2005. Placentation in the paca (Agouti paca L.). Reprod. Biol. Endocrinol. 3:9.

Calarco P.G. \& Moyer F.H. 1966. Structural changes in the murine yolk sac during gestation: cytochemical and electron microscope observations. J. Morphol. 119:341-357.

Carter A.M. 2001. Evolution of the placenta and fetal membranes seen in the light of molecular phylogenetics. Placenta 22:800-807.

Carter A.M. 2007. Animal models of human placentation: a review. Placenta 21:41-47.

Conceição R.A., Ambrósio C.E., Martins D.S., Carvalho A.F., Franciolli A.L.R., Machado M.R.F., Oliveira M.F. \& Miglino M.A. 2008. Aspectos morfológicos do saco vitelino em roedores da subordem Hystricomorpha: paca (Agouti paca) e cutia (Dasyprocta aguti). Pesq. Vet. Bras. 28(5):253259.

Cross J.C. 1998. Formation of the Placenta and Extraembryonic Membranes. Annals N.Y. Acad. Sci. 857:23-32.

Dempsey E.W. 1953. Electron microscopy of the visceral yolk-sac epithelium of the guinea pig. Am. J. Anat. 93(3):331-363.

Favaron P.O., Carter A.M., Ambrósio C.E., Morini A.C., Mess A.M., Oliveira M.F. \& Miglino M.A. 2011. Placentation in Sigmodontinae: a rodent taxon native to South America. Reprod. Biol. Endocrinol. 9:55.

Favaron P.O., Carter A.M., Mess A.M., Oliveira M.F. \& Miglino M.A. 2012. An unusual feature of yolk sac placentation in Necromys lasiurus (Rodentia, Cricetidae, Sigmodontinae). Placenta 33:578-580.

Favaron P.O., Mess A.M., Oliveira M.F., Gabory A., Miglino M.A., Chavatte-Palmer P. \& Tarrade A. 2013. Morphometric analysis of the placenta in the New World mouse Necromys lasiurus (Rodentia, Cricetidae): a comparison of placental development in cricetids and murids. Reprod. Biol. Endocrinol. 11:10.

Freyer C. \& Renfree M.B. 2009. The mammalian yolk sac placenta. J. Exp. Zoology, Mol. Dev. Evol. 312B:545-554. 
Haar J.L. \& Ackerman G.A. 1971. Ultrastructural changes in mouse yolk sac associated with initiation of vitelline circulation. Anat. Rec. 170(4):437455

Holson J., Stump D., Pearce L., Watson R. \& DeSesso J. 2005. Mode of Action: yolk sac poisoning and impeded histiotrophic nutrition-HBOC-related congenital malformations. Crit. Rev. Toxicol. 35:739-745.

Jollie W.P. 1968. Changes in the fine structure of the parietal yolk sac of the rat placenta with increasing gestacional age. Am. J. Anat. 122:513-532.

Jollie W.P. 1990. Development, morphology, and function of the yolk-sac placenta of laboratory rodents. Teratology 41:361-381.

King B.F. \& Enders A.C. 1970. The fine structure of the guinea pig yolk sac placenta. Am. J. Anat. 127(4):397-413.

King B.F. 1971. Differentiation of parietal endoderm cells of the guinea pig yolk sac, with particular reference to the development of endoplasmic reticulum. Devtl Biol. 26:547-559.

King B.F. 1982. A freeze-fracture study of the guinea pig yolk sac epithelium. Anat. Rec. 202:221-230.

Laliberté F., Muccielli A. \& Laliberté M.F. 1984. Dynamics of antibody transfer from mother to fetus through the yolk sac in the rat. Biol. Cell. 50:255-261

Miglino M.A., Franciolli A.L.R., Oliveira M.F., Ambrósio C.E., Bonatelli M., Machado M.R.F. \& Mess A. 2008. Development of the inverted visceral yolk sac in three species of caviids (Rodentia, Caviomorpha, Caviidae). Placenta 29:748-752.

Miglino M.A., Carter A.M., Ambrósio C.E., Bonatelli M., Oliveira M.F., Santos
Ferraz R.H., Rodrigues R.F. \& Santos T.C. 2004. Vascular organization of the hystricomorph placenta: a comparative study in the agouti, capybara, guinea pig, paca and rock cavy. Placenta 25:438-48.

Mossman H.W. 1987. Vertebrate Fetal Membranes: comparative ontogeny and morphology, evolution, phylogenetic significance, basic functions, research opportunities. MacMillan Press, London.

Oliveira M.F., Carter A.M., Bonatelli M., Ambrósio C.E. \& Miglino M.A. 2006. Placentation in the rock cavy, Kerodon rupestris (Wied). Placenta 27:8797.

Oliveira M.F., Mess A., Ambrosio C.E., Dantas C.A.G., Favaron P.O. \& Miglino M.A. 2008. Chorioallantoic placentation in Galea spixii (Rodentia, Caviomorpha, Caviidae). Reprod. Biol. Endocrinol. 6:1-8.

Oliveira M.F., Favaron P.O., Ambrósio C.E., Miglino M.A. \& Mess A.M. 2012a. Chorioallantoic and Yolk Sac Placentation in Thrichomys laurentinus (Echimyidae) and the Evolution of Hystricognath Rodents. J. Exp. Zool. B, Mol. Dev. Evol. 318B:13-25.

Oliveira M.F., Vale A.M., Favaron P.O., Vasconcelos B.G., Oliveira G.B., Miglino M.A. \& Mess A. 2012b. Development of yolk sac inversion in $\mathrm{Ga}$ lea spixii and Cavia porcellus (Rodentia, Caviidae). Placenta 33:878881.

Sansom G.S. 1922. Early development and placentation in Arvicola (Microtus) amphibius, with special reference to the origin of placental giant cells. J. Anat. 56:333-365.

Wislocki G.B., Deane W. \& Dempsey E.W. 1946. The histochemistry of the rodent's placenta. Am. J. Anat. 78:281-347. 